\title{
Tailored ionic liquid-based surfactants for the formation of microemulsions with water and a hydrophobic ionic liquid $\dagger$
}

Cite this: Soft Matter, 2016, 12,6352

Received 19th April 2016, Accepted 5th July 2016

DOI: 10.1039/c6sm00930a

www.rsc.org/softmatter

Microemulsions ( $\mu$ e) with water and a hydrophobic ionic liquid (IL) usually require 45-60 wt\% surfactant to solubilize equal amounts of water and IL. To increase the efficiency we designed a new class of surfactants by combining a hydrophilic but IL-ophobic carbohydratebased part with a hydrophobic but IL-ophilic IL-based part. These surfactants allow formulating microemulsions with 20 wt\% surfactant only which opens up a new arena for efficient water-IL $\mu$ es.

Conventional, commercially available surfactants self-assemble in $\mathrm{H}_{2} \mathrm{O},{ }^{1}$ in hydrophilic ionic liquids (ILs), ${ }^{2-5}$ and in hydrophobic ILs, ${ }^{6,7}$ i.e. they form micelles. In all three cases selfassembly is caused by the solvophobic interaction between the solvent and the hydrocarbon chain of the surfactant. We will come back to this important point further below. Conventional surfactants can also self-assemble in the presence of two (or more) solvents, which is the basis for the formation of water-oil and IL-oil microemulsions ( $\mu$ e). In the latter case the IL must be lipophobic. The hydrophilic ILs 1-butyl-3-methylimidazolium tetrafluoroborate $\left([\mathrm{BMIm}] \mathrm{BF}_{4}\right)^{8-15}$ and ethylammonium nitrate $(\mathrm{EAN})^{12,16-19}$ are the two most commonly used ILs for the formulation of IL-oil $\mu$ es. To the best of our knowledge, the only "task" conventional surfactants cannot carry out is forming efficient water-IL $\mu$ es. The majority of all investigations were carried out with the hydrophobic IL 1-butyl-3-methylimidazolium hexafluorophosphate [BMIm] $\mathrm{PF}_{6}{ }^{20-25}$ and it was found that very high amounts of surfactant are required to formulate a one-phase

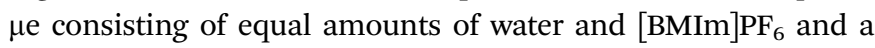
nonionic surfactant whose head group contains ethyleneoxide (EO) units. Note that a low efficiency is always connected with a weakly structured system and eventually with the total loss of microstructure ${ }^{26}$

Universität Stuttgart, Institut für Physikalische Chemie, Pfaffenwaldring 55, 70569 Stuttgart, Germany.E-mail: cosima.stubenrauch@ipc.uni-stuttgart.de

$\dagger$ Electronic supplementary information (ESI) available: Sample preparation, the experimental procedure to measure the phase diagrams, the synthesis of the IL-based surfactants, the ROESY spectrum, a SAXS curve of the microemulsion as well as phase triangles with $\mathrm{C}_{12} \mathrm{E}_{6}$ and the new surfactants are supplied. See DOI: 10.1039/c6sm00930a

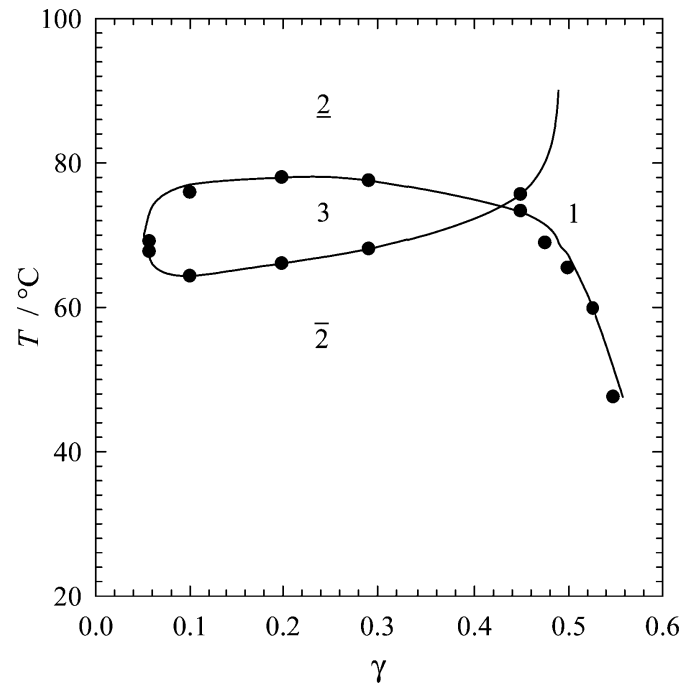

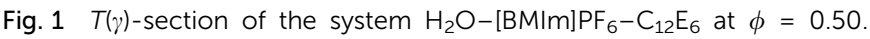
The numbers denote three (3) and two (2) coexisting phases, respectively, while 1 stands for a one-phase microemulsion. In 3 the middle phase, in $\underline{2}$ the lower phase, and in $\overline{2}$ the upper phase contains most of the surfactant.

In Fig. 1 one sees a typical "fish-like" phase diagram of such a ternary system. This diagram is obtained by measuring the phase boundaries as a function of the temperature $T$ and the total surfactant concentration $\gamma\left(\gamma=m_{\text {sur }} / m_{\text {total }}\right)$ for equal volumes of water and a hydrophobic solvent, ${ }^{27}$ which in our case is an IL $\left(\phi=V_{\mathrm{IL}} /\left(V_{\mathrm{IL}}+V_{\mathrm{H}_{2} \mathrm{O}}\right)=0.5\right)$. The system shown in Fig. 1 consists of $\mathrm{H}_{2} \mathrm{O},[\mathrm{BMIm}] \mathrm{PF}_{6}$, and the nonionic surfactant hexaethyleneglycol monododecyl ether $\mathrm{C}_{12} \mathrm{E}_{6}$ (see Fig. 2a). What is of importance for our proof of concept is the fact that around $45 \mathrm{wt} \% \mathrm{C}_{12} \mathrm{E}_{6}$ are required to solubilize equal volumes of water and IL in one phase (1), i.e. the surfactant is very inefficient! Attempts to increase the efficiency by increasing the hydrophobicity of the IL failed. ${ }^{28,29}$ Despite the low efficiency it is claimed in all studies that the system $\mathrm{H}_{2} \mathrm{O}-[\mathrm{BMIm}] \mathrm{PF}_{6}-\mathrm{TX} 100$ forms "normal" $\mu$ es, i.e. the formation of IL droplets in water, water droplets in IL 

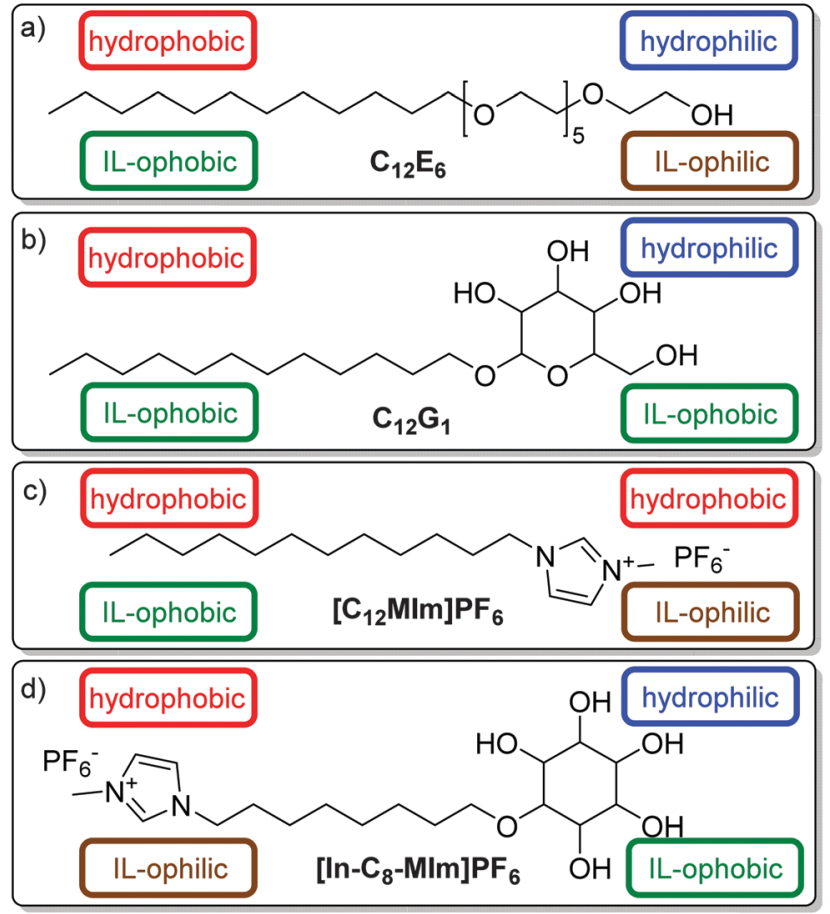

Fig. 2 Solvophilicity/solvophobicity contrast of different surfactants with respect to water and a hydrophobic IL. (a) Alkyl ethoxylate, (b) alkyl carbohydrate, (c) alkylated IL, (d) carbohydrated IL.

and bicontinuous phases is postulated. However, an indisputable experimental proof is provided in none of these studies.

We are aware of a couple of studies which are not in line with this picture. (1) For example, Behera et al. ${ }^{22}$ found for the system $\mathrm{H}_{2} \mathrm{O}-\left[\mathrm{BMIm}^{-} \mathrm{PF}_{6}-\mathrm{TX}_{100}\right.$ that the EO head group of the nonionic surfactant TX100 interacts with $\left[\mathrm{BMIm}^{2} \mathrm{PF}_{6}\right.$. Since at

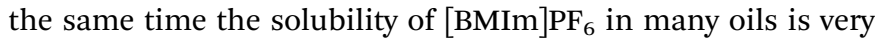
limited it is argued that the formation of a $\mu$ e where $\mathrm{H}_{2} \mathrm{O}$ and IL are separated by a surfactant monolayer is very unlikely because the hydrophobic chain is compatible neither with the IL nor with water. They suggest that the IL is accumulated in the palisade layer, i.e. in the layer formed by the head groups of the TX-100 micelles. Further experimental evidence for this scenario was provided by our group only recently. ${ }^{30}$ (2) Zech and Kunz ${ }^{31}$ summarize everything they read about water-IL $\mu$ es with the sentence "... knowledge gained from classical water/ oil/surfactant systems cannot readily be transferred to aqueous $\mu$ es with ionic liquids as nonpolar phase." This is an important statement since the opposite holds true for $\mu$ es where the IL replaces water: in this case the general rules are exactly the same as for classical water/oil/surfactant systems. ${ }^{16,18,19}$ (3) Inoue and Misono ${ }^{32}$ studied the change of the cloud point temperature $T_{\mathrm{C}}$ in mixtures of [BMIm] $\mathrm{PF}_{6}$ and $\mathrm{C}_{i} \mathrm{E}_{j}$ surfactants, which differ in the length of the alkyl- and EO-chain. They clearly demonstrated that the alkyl chain is IL-ophobic, while the EO-chain is IL-ophilic.

As already mentioned, we carried out an extensive study with the system $\mathrm{H}_{2} \mathrm{O}-[\mathrm{BMIm}] \mathrm{PF}_{6}-\mathrm{TX} 100$ and found no experimental evidence for the formation of traditional microemulsions. ${ }^{30}$
We speculate that the same holds true for the system seen in Fig. 1. What hinders $\mu$ e formation?

We recall that the alkyl chain of a conventional surfactant is not only hydrophobic but also "IL-ophobic" (Fig. 2a and b), thus this surfactant will not assemble at the interface between water and $[\mathrm{BMIm}] \mathrm{PF}_{6}$. The surfactant required for the formulation of a water-IL $\mu$ e must consist of a hydrophilic part, which is "IL-ophobic", and an "IL-ophilic" part, which is hydrophobic! Our aim was to formulate an efficient $\mu$ e consisting of $\mathrm{H}_{2} \mathrm{O}$, [BMIm] $\mathrm{PF}_{6}$, and a tailored surfactant. The strategy for the design of the surfactant was to combine a carbohydrate group, namely an inositol group, with a hydrophobic IL group (Fig. 2d). The reason for choosing a carbohydrate head group was the fact that carbohydrates are well water soluble but only very poorly soluble in most BMIm-based ILs as opposed to ethyleneoxide groups which are soluble in both $\mathrm{H}_{2} \mathrm{O}$ and IL. Even more, carbohydrates can be used to "salt out" $[\mathrm{BMIm}] \mathrm{BF}_{4}$ from aqueous solutions. ${ }^{33,34}$ A ROESY spectrum of the ternary system indeed shows that there are no interactions between the carbohydrate head group and the IL (see ESI $\dagger$ ). For the IL group we decided to take a motif similar

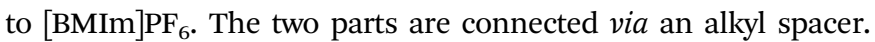
The rationale behind this design was to have a hydrophilic but IL-ophobic carbohydrate-based part and a hydrophobic (and lipophobic) but IL-ophilic IL-based part. Note that we introduce the concept of being IL-ophilic and IL-ophobic, respectively, since the argument hydrophobic $=$ lipophilic does not hold true when an IL is used as oil. In the study at hand we present the first two examples of such IL-based surfactants which we synthesized in our group according to Scheme 1 and which we tested as regards their efficiency to solubilize equal volumes of water and [BMIm] $\mathrm{PF}_{6}$. (For the sake of completeness we like to mention that surfactants with an IL-based head group and a long hydrocarbon chain (Fig. 2c) were synthesized and successfully used to formulate IL-oil $\mu$ es. ${ }^{12,13,17}$ However, these surfactants still contain a hydrocarbon chain which - as already mentioned - is both hydrophobic and IL-ophobic.) The two IL-based surfactants differ in the length of the alkyl spacer, which is $n=8$ for $\left[\mathrm{In}-\mathrm{C}_{8}-\mathrm{MIm}\right] \mathrm{PF}_{6}$

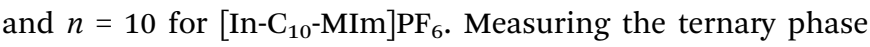

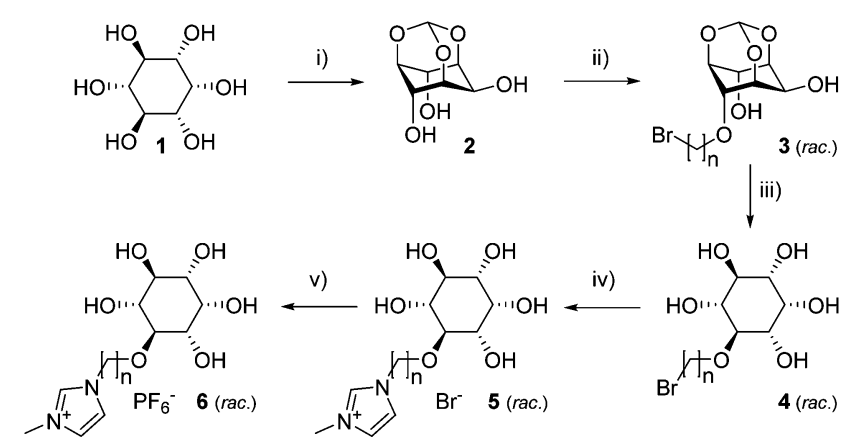

Scheme 1 Synthesis of the IL-based surfactant. (i) Triethyl orthoformate, $p$-TsOH, DMF, $100{ }^{\circ} \mathrm{C}, 6 \mathrm{~h}, 87 \%$; (ii) $1 \mathrm{NaH}, 2 \mathrm{BrC}_{n} \mathrm{H}_{2 n+1} \mathrm{Br}$, DMF, r.t. to $100{ }^{\circ} \mathrm{C}, 14 \mathrm{~h}, 63 \%(n=8), 46 \%(n=10)$; (iii) $\mathrm{HCl}, \mathrm{H}_{2} \mathrm{O}, 80{ }^{\circ} \mathrm{C}, 2 \mathrm{~h}, 91 \%(n=8)$, 93\% ( $n=10$ ); (iv) $\mathrm{N}$-methyl imidazole, $80{ }^{\circ} \mathrm{C}, 14 \mathrm{~h}, 99 \%(n=8), 99 \%$ $(n=10)$; (v) $\mathrm{PF}_{6}{ }^{-}$-loaded anion exchange resin (Amberlyst A26) $90 \%(n=8)$, $88 \%(n=10)$. The synthesis is described in detail in the ESI. $\dagger$ 


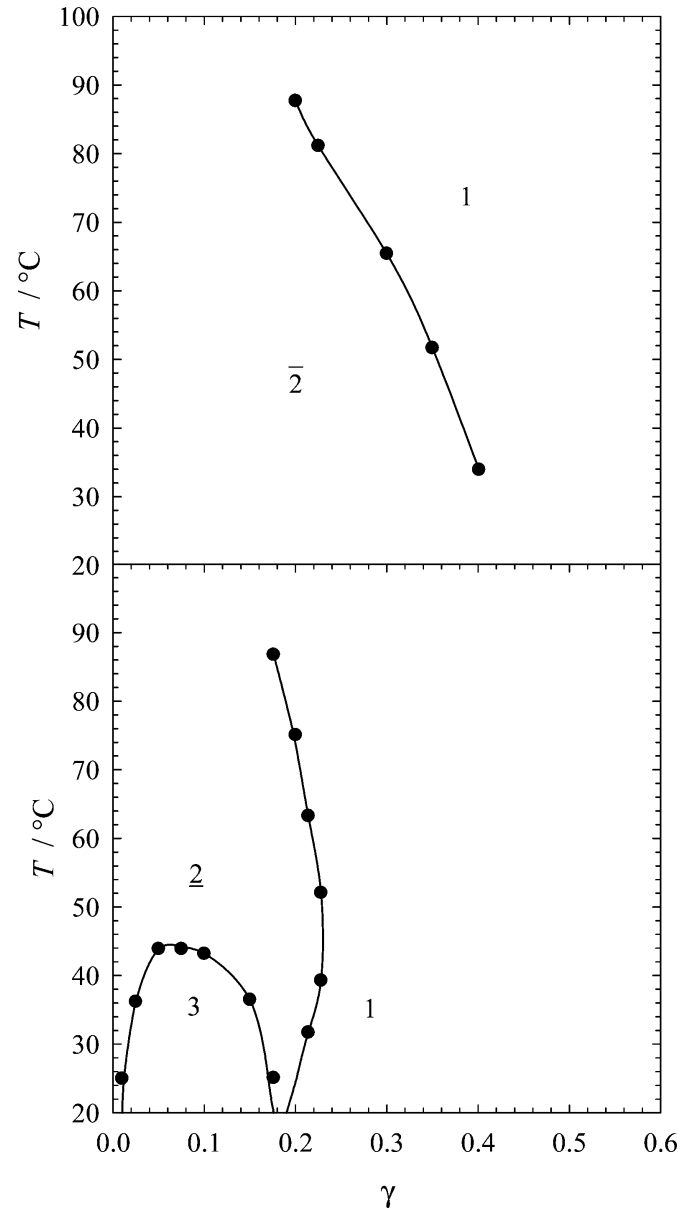

Fig. 3 Top: $T(\gamma)$-section of the system $\mathrm{H}_{2} \mathrm{O}-\left[\mathrm{BMIm}_{\mathrm{P}} \mathrm{F}_{6}-\left[\mathrm{In}-\mathrm{C}_{8}-\mathrm{MIm}_{\mathrm{P}} \mathrm{PF}_{6}\right.\right.$ at $\phi=0.50$. Bottom: $T(\gamma)$-section of the system $\mathrm{H}_{2} \mathrm{O}-[\mathrm{BMIm}] \mathrm{PF}_{6}-\left[\mathrm{In}-\mathrm{C}_{10^{-}}\right.$ $\mathrm{MIm}_{\mathrm{P}} \mathrm{F}_{6}$ at $\phi=0.50$.

diagrams as a function of $T$ and $\gamma$ at a fixed $1: 1$ volume ratio $(\phi=0.50)$ of the two solvents one obtains the phase boundaries seen in Fig. 3. For $n=8$ (Fig. 3, top) we observed one phase boundary separating a two-phase (2) from a one-phase (1) region. The former consists of a lower IL excess phase and an upper IL-inwater $\mu$ e. For $n=10$ (Fig. 3, bottom) things are different.

Here the two-phase region (2) consists of an upper water excess phase and a lower water-in-IL $\mu$ e. In addition, a threephase region (3) is present. Assuming that our system behaves like a traditional ternary water-oil-surfactant system one can argue as follows: the surfactant with the $\mathrm{C}_{8}$ spacer bends around the IL (curvature $H>0$ ), while the one with the $\mathrm{C}_{10}$ spacer bends around water $(H<0)$. For the formulation of an efficient $\mu \mathrm{e}$, however, we need a surfactant that is able to form a layer with an average curvature of zero $(H=0) .^{35}$ The two new surfactants are obviously not able to fulfil this requirement. However, since we are talking about a surfactant with a tendency to bend around the IL $(H>0)$ and one with the tendency to bend around water $(H<0)$ there must be a certain ratio at which a mixed layer with $H=0$ is formed.

We thus measured the phase diagram as a function of the surfactant ratio $\left(\delta=m_{\mathrm{C}_{10}} /\left(m_{\mathrm{C}_{10}}+m_{\mathrm{C}_{8}}\right)\right)$ and the total surfactant concentration at $\phi=0.50$ and $T=50{ }^{\circ} \mathrm{C}$. The reason for choosing this temperature becomes obvious if one looks at Fig. 3: at $T=50{ }^{\circ} \mathrm{C}$ the surfactant $\left[\mathrm{In}-\mathrm{C}_{8}-\mathrm{MIm}\right] \mathrm{PF}_{6}$ is bend around the $\mathrm{IL}$, while [In- $\left.\mathrm{C}_{10}-\mathrm{MIm}\right] \mathrm{PF}_{6}$ is bend around water. Thus mixing these two surfactants at $50{ }^{\circ} \mathrm{C}$ allows one to change the curvature from being bend around the IL to being bend around water with

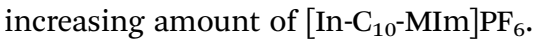

Indeed, our mixing strategy led to the expected result, namely to an efficient $\mu$ e (only $20 \mathrm{wt} \%$ surfactant are required for the formation of the one-phase region as compared to $45 \mathrm{wt} \%$ for conventional surfactants) whose curvature can be tuned via the surfactant ratio. The presence of a nanostructure was confirmed by SAXS measurements (see ESI $\dagger$ ). Looking at Fig. 4 (top) one sees that the ratio required to form a layer with an average curvature of zero is $\delta=0.8$, which, in turn, corresponds to an average spacer length of 9.6! Since this spacer length cannot be synthesized the formulation must be based on this mixing "trick", a trick which is well known for trimming phase behaviour towards a desired direction. ${ }^{36,37}$ The final phase diagram we measured was another $T(\gamma)$-section where the surfactant consisted of a mixture of the two new IL-based surfactants at a ratio of $\delta=0.8$ (see Fig. 4 (bottom)). At this ratio

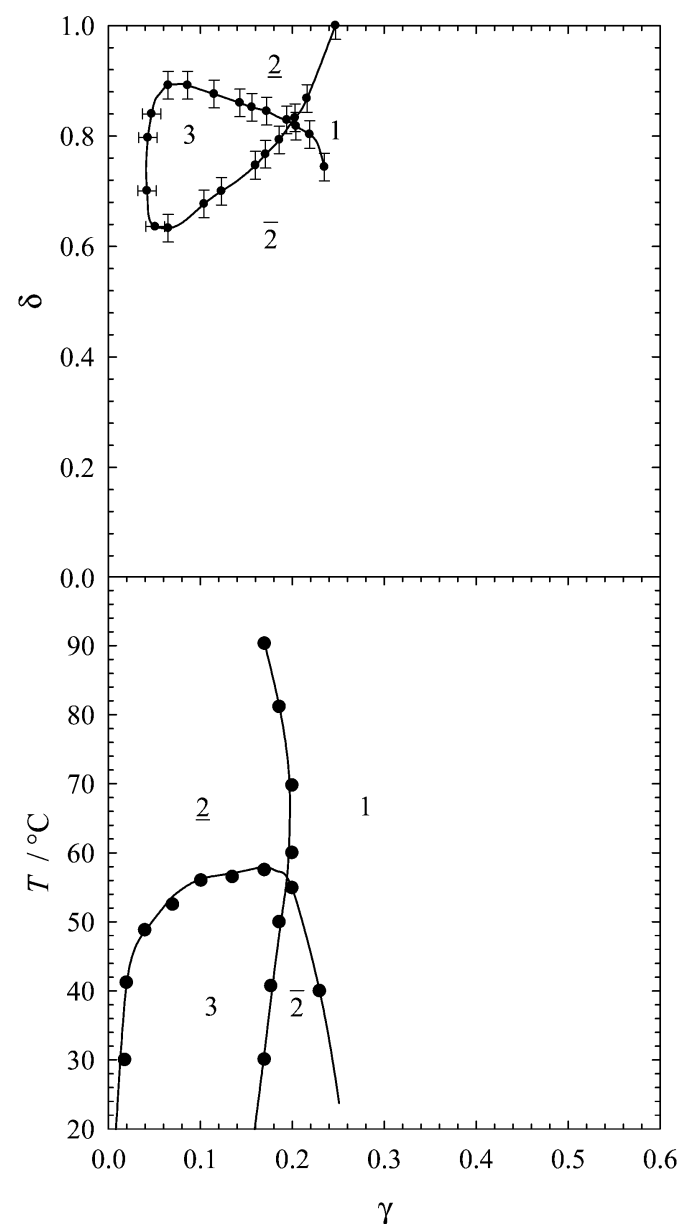

Fig. 4 Top: $\delta(\gamma)$-section of the system $\mathrm{H}_{2} \mathrm{O}-\left[\mathrm{BMIm}^{\mathrm{P}} \mathrm{PF}_{6}-\left[\mathrm{In}-\mathrm{C}_{8}-\mathrm{MIm}\right] /[\mathrm{In}-\right.$ $\mathrm{C}_{10}-\mathrm{MImJPF}_{6}$ at $50{ }^{\circ} \mathrm{C}$ and $\phi=0.50$. Bottom: $T(\gamma)$-section of the system $\mathrm{H}_{2} \mathrm{O}-\left[\mathrm{BMIm}_{\mathrm{P}} \mathrm{F}_{6}-\left[\mathrm{In}-\mathrm{C}_{8}-\mathrm{MIm}\right] /\left[\mathrm{In}-\mathrm{C}_{10}-\mathrm{MIm}_{\mathrm{P}} \mathrm{PF}_{6}\right.\right.$ at $\delta=0.8$ and $\phi=0.50$. 
it is indeed possible to bend the curvature of the surfactant layer from $H>0$ over $H=0$ to $H<0$ with increasing temperature!

Let us conclude with an outlook. We showed that it is possible to tailor-make surfactants which allow forming efficient water-IL $\mu$ es. This proof of concept is the first of its kind and we hope that it triggers new research activities in the field of surfactant design! To further increase the efficiency we will play around with the surfactant's side chain. Replacing the methyl group of the IL-unit e.g. by a propyl group is expected to decrease the monomeric solubility of the surfactant in water and thus increase its efficiency. (A phase triangle is shown in the ESI. $\dagger$ ) An alternative may be to replace the alkyl spacer by a propyleneoxide unit. In addition, we will challenge our new surfactants as regards their ability to microemulsify other water-IL couples. Once we know how to design surfactants for the formulation of efficient $\mathrm{H}_{2} \mathrm{O}$-IL $\mu$ es detailed studies of the structures will follow including SANS, self-diffusion NMR and transmission electron microscopy. Here, however, we do not expect any surprises but general patterns as those known from the oil-containing counterparts.

Once this research area is established, a complete new arena opens up as regards applications. Water-IL $\mu$ es can be used, for example, as reaction media for enzymatic reactions or for the synthesis of nanoparticles (NPs). The major benefit of water-IL microemulsions over water-oil microemulsions is the fact that a lot of reactants used for either enzymatic reactions or NP synthesis dissolve better in ILs than in conventional oils. Moreover, ILs are considered green solvents due to their low flammability and low vapour pressure. Thus, when aiming to use water-IL microemulsions as reaction media, both the number of substrates is widened and accident hazard and ecological risk are reduced. For enzymatic reactions, the combination of membrane-bound enzymes, being active at the water-IL interface, with substrates which are poorly soluble in water or oil but well soluble in ILs is of enormous interest. One example of such an important substrate class are polar poly-aromatics. The presence of an IL may also increase the stability and catalytic activity of the generated metal NPs since it is known that imidazolium-based ILs tend to stabilize the NPs and prevent agglomeration. ${ }^{38,39}$ Another highly promising application is the use of these microemulsions as pseudostationary phase (PSP) in "microemulsion electrokinetic chromatography" (MEEKC). Conventional microemulsions with chiral surfactants are successfully used as PSP for MEEKC for the separation of racemates. ${ }^{40}$ On the other hand, it was found that the usage of an IL as additive in a non-chiral MEEKC increases the efficiency of the separation. ${ }^{41,42}$ Thus, the separation efficiency is expected to increase even further if one combines these two ideas, i.e. if one formulates chiral IL-in-water microemulsions. Though the currently used surfactant was synthesized as a racemate, carbohydrates are an ideal platform to generate cost-efficient chiral surfactants from the natural chiral pool.

We thank PD Dr Thomas Sottmann for many fruitful discussions. We acknowledge funding from the Deutsche Forschungsgemeinschaft (STU 287/3-1).

\section{Notes and references}

1 D. F. Evans and H. Wennerström, The Colloidal Domain: Where Physics, Chemistry, Biology, and Technology Meet, Wiley-VCH, Weinheim, 2nd edn, 1999.

2 D. F. Evans, A. Yamauchi, G. J. Wei and V. A. Bloomfield, J. Phys. Chem., 1983, 87, 3537-3541.

3 J. Hao and T. Zemb, Curr. Opin. Colloid Interface Sci., 2007, 12, 129-137.

4 T. L. Greaves and C. J. Drummond, Chem. Soc. Rev., 2008, 37, 1709.

5 T. L. Greaves, A. Weerawardena, C. Fong, I. Krodkiewska and C. J. Drummond, J. Phys. Chem. B, 2006, 110, 22479-22487.

6 J. L. Anderson, V. Pino, E. C. Hagberg, V. V. Sheares and D. W. Armstrong, Chem. Commun., 2003, 2444-2445.

7 K. A. Fletcher and S. Pandey, Langmuir, 2004, 20, 33-36.

8 H. X. Gao, J. C. Li, B. X. Han, W. N. Chen, J. L. Zhang, R. Zhang and D. D. Yan, Phys. Chem. Chem. Phys., 2004, 6, 2914-2916.

9 J. Eastoe, S. Gold, S. E. Rogers, A. Paul, T. Welton, R. K. Heenan and I. Grillo, J. Am. Chem. Soc., 2005, 127, 7302-7303.

10 Y. Gao, N. Li, L. Zheng, X. Zhao, J. Zhang, Q. Cao, M. Zhao, Z. Li and G. Zhang, Chem. - Eur. J., 2007, 13, 2661-2670.

11 Y. Gao, N. Li, S. Zhang, L. Zheng, X. Li, B. Dong and L. Yu, J. Phys. Chem. B, 2009, 113, 1389-1395.

12 O. Zech, S. Thomaier, P. Bauduin, T. Rück, D. Touraud and W. Kunz, J. Phys. Chem. B, 2009, 113, 465-473.

13 Z. Chen, F. Yan, L. Qiu, J. Lu, Y. Zhou, J. Chen, Y. Tang and J. Texter, Langmuir, 2010, 26, 3803-3806.

14 R. D. Falcone, B. Baruah, E. Gaidamauskas, C. D. Rithner, N. M. Correa, J. J. Silber, D. C. Crans and N. E. Levinger, Chem. - Eur. J., 2011, 17, 6837-6846.

15 F. Wang, Z. Zhang, D. Li, J. Yang, C. Chu and L. Xu, J. Chem. Eng. Data, 2011, 56, 3328-3335.

16 R. Atkin and G. G. Warr, J. Phys. Chem. B, 2007, 111, 9309-9316.

17 O. Zech, S. Thomaier, A. Kolodziejski, D. Touraud, I. Grillo and W. Kunz, Chem. - Eur. J., 2010, 16, 783-786.

18 J. C. Thater, V. M. F. Gérard and C. Stubenrauch, Langmuir, 2014, 30, 8283-8289.

19 J. C. Thater, T. Sottmann and C. Stubenrauch, Colloids Surf., A, 2016, 494, 139-146.

20 Y. Gao, S. Han, B. Han, G. Li, D. Shen, Z. Li, J. Du, W. Hou and G. Zhang, Langmuir, 2005, 21, 5681-5684.

21 Y. Gao, N. Li, L. Zheng, X. Zhao, S. Zhang, B. Han, W. Hou and G. Li, Green Chem., 2006, 8, 43-49.

22 K. Behera, P. Dahiya and S. Pandey, J. Colloid Interface Sci., 2007, 307, 235-245.

23 N. Anjum, M. A. Guedeau-Boudeville, C. Stubenrauch and A. Mourchid, J. Phys. Chem. B, 2009, 113, 239-244.

24 K. Behera, V. Kumar and S. Pandey, ChemPhysChem, 2010, 11, 1044-1052.

25 L. Xue, H. Qiu, Y. Li, L. Lu, X. Huang and Y. Qu, Colloids Surf., B, 2011, 82, 432-437.

26 M. Kahlweit, R. Strey and G. Busse, Phys. Rev. E: Stat. Phys., Plasmas, Fluids, Relat. Interdiscip. Top., 1993, 47, 4197-4209. 
27 M. Kahlweit and R. Strey, Angew. Chem., Int. Ed. Engl., 1985, 24, 655-669.

28 J. H. Porada, M. Mansueto, S. Laschat and C. Stubenrauch, Soft Matter, 2011, 7, 6805-6810.

29 K. Yan, Y. Sun and X. Huang, $R S C A d v$., 2014, 4, 32363-32370.

30 H. Bilgili, M. Bürger, C. Stubenrauch and J. H. Porada, Soft Matter, 2016, submitted.

31 O. Zech and W. Kunz, Soft Matter, 2011, 7, 5507-5513.

32 T. Inoue and T. Misono, J. Colloid Interface Sci., 2009, 337, 247.

33 Y. Chen, Y. Wang, Q. Cheng, X. Liu and S. Zhang, J. Chem. Thermodyn., 2009, 41, 1056-1059.

34 M. G. Freire, C. L. S. Louros, L. P. N Rebelo and J. A. P. Coutinho, Green Chem., 2011, 13, 1536.
35 R. Strey, Colloid Polym. Sci., 1994, 272, 1005-1019.

36 C. Stubenrauch, S. Burauer, R. Strey and C. Schmidt, Liq. Cryst., 2004, 31, 39-53.

37 D. Varade, H. Kunieda, R. Strey and C. Stubenrauch, J. Colloid Interface Sci., 2006, 300, 338-347.

38 J. Dupont and J. D. Scholten, Chem. Soc. Rev., 2010, 39, 1780-1804.

39 C. Vollmer and C. Janiak, Coord. Chem. Rev., 2011, 255, 2039-2057.

40 K. A. Kahle and J. P. Foley, Electrophoresis, 2007, 28, 2503-2526.

41 S. M. Mwongela, N. Siminialayi, K. A. Fletcher and I. M. Warner, J. Sep. Sci., 2007, 30, 1334-1342.

42 J. Cao, H. Qu and Y. Cheng, Electrophoresis, 2010, 31, 3492-3498. 